\title{
Effects of Thyroxine and Thiourea on the Development of Larval Red Sea Bream Pagrus major ${ }^{* 1}$
}

\author{
Yasushi Hirata, ${ }^{* 2}$ Hisashi Kurokura, ${ }^{* 2}$ and Shogoro Kasahara*2 \\ (Received January 26, 1989)
}

\begin{abstract}
The role of thyroid hormone on the development of larval and early juvenile red sea bream was studied by administrating thyroxine $\left(T_{4}\right)$ and thiourea (TU) as an anti-thyroidal agent. $T_{4}$ treatment accelerated the appearance of black stripes on the body and the change in the habitat from the surface to the bottom of the aquarium. In contrast, TU treatment caused stasis of black stripes formation and delayaed the change in the habitat. These results indicate that thyroid hormone plays the role of an inducer in the morphological and behavioral transformation from post-larva to juvenile in red sea bream.
\end{abstract}

The red sea bream Pagrus major is one of the most important commercial fish species in Japan. Aritificial seed production for intensive culture and stocking in the natural environment has already been performed actively these two decades. As such activity has progressed, biological information on the early life history of the red sea bream has been reported by many investigators. ${ }^{1-122}$

In view of the increasing importance of this fish, however, the present information on the early life history is not sufficient for the stable production of normal seed and the control of larval growth and development. Moreover, little literature is available on the role of the endocrine glands in the larval development of marine fish species. Recently, Inui and Miwa ${ }^{13)}$ found that the metamorphosis of flounder larvae can be controlled by the administration of thyroxine, and that hormonal control is present in the early development of these larvae. It is well-known that in the flounder, metamorphosis from a symmetrical shape to an asymmetrical shape occurs along with a behavioral change from the pelagic to benthic habit. Fukuhara ${ }^{5)}$ has reported the metamorphosis of the red sea bream, indicating that the transformation from the post-larva to juvenile stage occurred during the period from 7.6 to $8.6 \mathrm{~mm}$ in standard length, and that during this phase, various organs e.g., fins, scales, black stripes on the body surface and pyloric caeca, developed. Furthermore, the swimming ability was enhanced and transformation of the habitat from surface to benthic layer occurred. It is quite plausible that these larval developments in the red sea bream are controlled by hormones as in the flounder larvae.

The purpose of this study was to clarify the existence of hormonal control in the early development of larval red sea bream by investigating the effects of thyroxine and thiourea on morphological and behavioral changes of red sea bream.

\section{Materials and Methods}

Eggs of red sea bream were obtained from Hiroshima Prefectural Farming Fishery Association on 9 May 1986, and then transferred to the Hiroshima Prefectural Fisheries Experimental Station. Newly hatched larvae were initially reared in two 500- $l$ tanks supplied with running sea water at a density of 40,000 larvae $/ \mathrm{m}^{3}$. At 15 days after hatching, when the standard length had reached $4.8-5.7 \mathrm{~mm}$, the larvae were divided into four groups each consisting of 2,000 individuals (Experiment I). The following agents were then added directly into the seawater to create the experimental groups: $30 \mathrm{ppm}$ thiourea (TU; Nakarai Co., TU-I), $0.05 \mathrm{ppm}$ L-thyroxine sodium salt $\left(\mathrm{T}_{4} ;\right.$ Nakarai Co., $\left.\mathrm{T}_{4} 0.05-1\right), 0.1 \mathrm{ppm}$ $\mathrm{T}_{4}\left(\mathrm{~T}_{4}\right.$ 0.1-I) and no treatment (Control-I). Half of the aquarium water was replaced every other day, keeping the $T_{4}$ and $T U$ concentrations constant. $T_{4}$ treatment was terminated on the 34th day after hatching. TU-treated fish (TU-I) were

* Presented at the Meeting of the Japanese Society of Scientific Fisheries on October 4, 1986.

*2 Faculty of Applied Biological Science, Hiroshima University, Higashi-hiroshima 724, Japan

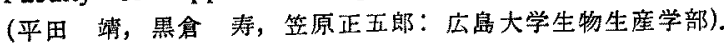


separated further on the same day into three groups (Experiment II). The following combinations of drugs were dissolved in ambient seawater as experimental treatments: $30 \mathrm{ppm}$ TU and $0.1 \mathrm{ppm} \mathrm{T} \mathrm{T}_{4}\left(\mathrm{TU}+\mathrm{T}_{4}-\mathrm{II}\right), 30 \mathrm{ppm}$ of TU (TUII) and no treatment (Control-II). These tretments were continued for six days.

The larvae were fed with rotifers from 4 to 30 days, and brine shrimp nauplii and wild copepods 17 to 41 days after hatching. Each experimental group was reared in a separate aerated circular plastic aquarium filled with $500 l$ of seawater. The water temperature was regulated at $20-22^{\circ} \mathrm{C}$.

The larvae were sampled from each aquarium at $16,18,20,22,24,26,28,30,32,34,39$ and 41 days after hatching, and preserved in $10 \%$ neutralized seawater formalin for later analysis. Preserved fish specimens were used for external morphological observations. The body dimensions measured were preanal length (PL); from the tip of the snout to the anus, standard length (SL); from the tip of the snout to the end of the notochord for the larval period, and to the base of the caudal fin for the juvenile specimens, total length (TL); from the tip of the snout to the posterior margin of the caudal fin. These were recorded using a profile projector. No correction was made to adjust size changes due to shrinkage caused by formalin fixation. For analysis of relationship between size and black stripes development, all specimens were classified into one of the seven developmental stages distinguished by Fukuhara.4)

\section{Results}

The growth curves for each of the experimental groups are shown in Fig. 1. Mean larval sizes in the four experimental tanks were nearly the same at the start of the experiment (about $5.0-5.6 \mathrm{~mm}$ SL). On day 34 , all experimental fish were about $10.5 \mathrm{~mm} \mathrm{SL}$; on day 41 , the mean length was about $14.5 \mathrm{~mm} \mathrm{SL}$. Throughout the experimental period, no significant differences were observed among the growth of all groups.

The ratio of PL to $T L$ in each experimental group (Experiment $\mathrm{I}$ ) is shown in Fig. 2. The ratio increased from $40 \% \mathrm{TL}$ to $45-47 \% \mathrm{TL}$ as the larvae grew, then became constant at 47$50 \%$ TL. However, no significant differences were recognized between each experimental group.

External morphological differences in each group caused by administration of $\mathrm{T}_{4}$ and TU included the length of elongated ventral fin-rays

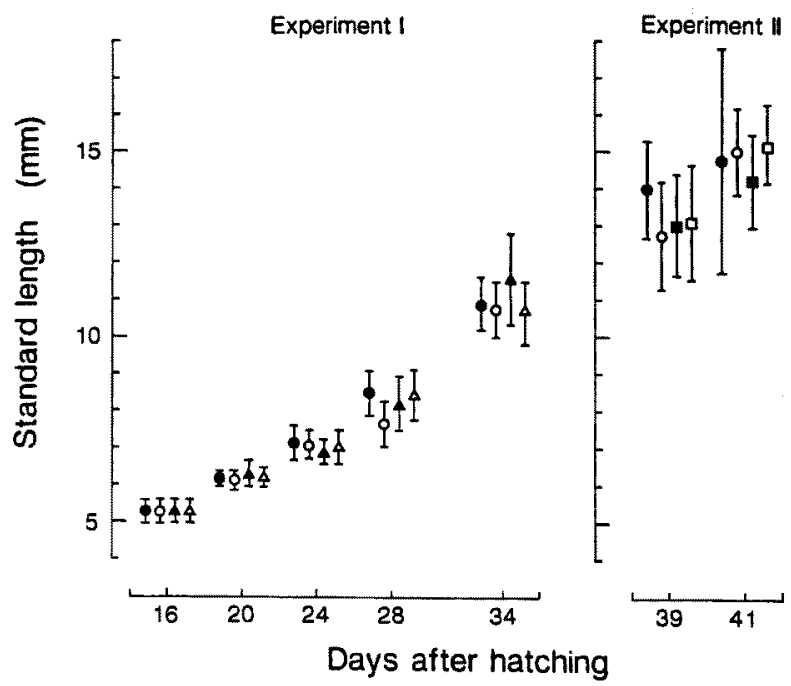

Fig. 1. Growth in standard length of red sea bream larvae during Experiments I and II. Symbols with vertical bars indicate means $\pm S D$.

: : Control-I (without drugs)

$O$ : TU-I and TU-II (30 ppm thiourea)

$\Delta: \mathrm{T}_{4}$ 0.1-I ( $0.1 \mathrm{ppm}$ thyroxine sodium salt)

$\triangle: T_{4} 0.05-1(0.05 \mathrm{ppm}$ of thyroxine sodium salt)

D: $\mathrm{TU}+\mathrm{T}_{4}-\mathrm{II}$ (30 ppm thiourea $+0.1 \mathrm{ppm}$ thyroxine)

$\square$ : Control-II (thiourea removed, Experiment II). 


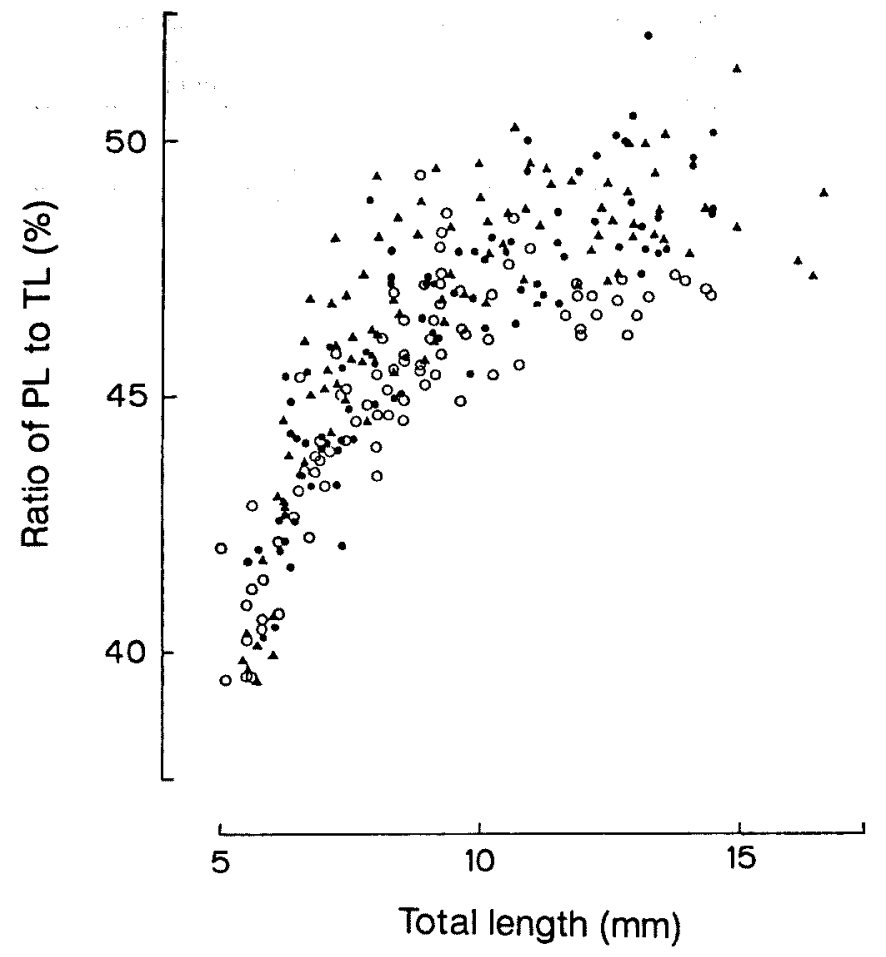

Fig. 2. Ratio of PL to TL during Experiment I. Solid circles, clear circles and solid triangles indicate individuals of Control-I, TU-I and $T_{4}$ 0.1-I, respectively.

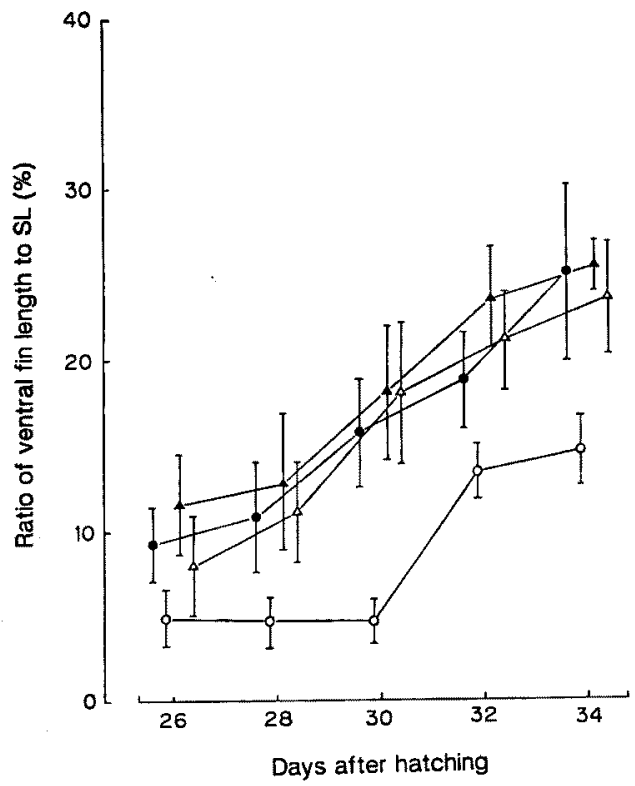

Fig. 3. Effect of thyroxine and thiourea on the length of the elongated ventral fin ray during Experiment I. Symbols are the same as in Fig. 1. The symbols and vertical bars indicate means $\pm S D$. and pigmentation of body surface.

The transition of the elongated ventral-fin length, in terms of the percent to SL for each experimental group is shown in Fig. 3. No significant difference was observed in the ratio between $T_{4}$-treated groups $\left(\mathrm{T}_{4} 0.05-\mathrm{I}\right.$ and $\left.\mathrm{T}_{4}, 0.1-\mathrm{I}\right)$ and Control-I, being about $24 \%$ SL at day 34 . The ratio for TU-I, however, was significantly $(p<0.001)$ shorter (about 14\% SL) than those of the other three groups.

In red sea bream larvae, pigmentation of body surface progressed by the appearance of chromatophores, e.g., melanophores, xanthophores, erythrophores and iridocytes. The melanophores form black stripes specific to the juvenile of red sea bream.4 The development of these stripes were applied as an index of the progress of pigmentation in the present experiment. Development of the black stripes in both experiments are shown in Table 1. $T_{4}$-treated fish $\left(T_{4} 0.05-I\right.$ and $\mathrm{T}_{4}$ 0.1-I) showed accelerated development in the formation of black stripes. At day 34, almost all fish in these groups had transformed to the juvenile, whereas TU-treated fish (TU-I) did not develop up to the final stage during the experi- 
Table 1. Distribution of black stripe stage on each sampling day

\begin{tabular}{|c|c|c|c|c|c|c|c|c|c|c|c|c|c|}
\hline & \multirow{3}{*}{ Stage } & \multicolumn{12}{|c|}{ Days after hatching } \\
\hline & & \multicolumn{9}{|c|}{ Experiment I } & & \multicolumn{2}{|c|}{ Experiment II } \\
\hline & & 18 & 20 & 22 & 24 & 26 & 28 & 30 & 32 & 34 & & 39 & 41 \\
\hline \multirow{7}{*}{ Cont.-I } & $G$ & & & & & & & & 3 & 5 & \multirow{7}{*}{ Cont.-I } & 10 & 10 \\
\hline & $F$ & & & & & & & 2 & 5 & 4 & & & \\
\hline & E & & & & & & & 2 & 1 & 1 & & & \\
\hline & D & & & & & & 2 & 4 & 1 & & & & \\
\hline & $\mathrm{C}$ & & & & & 1 & 2 & & & & & & \\
\hline & B & & & & & 4 & 5 & 1 & & & & & \\
\hline & A & 10 & 10 & 10 & 10 & 5 & 1 & 1 & & & & & \\
\hline \multirow{7}{*}{ TU-I } & $\mathrm{G}$ & & & & & & & & & & \multirow{7}{*}{ TU-II } & & \\
\hline & $\mathrm{F}$ & & & & & & & & & & & & \\
\hline & E & & & & & & & & & & & 1 & 1 \\
\hline & D & & & & & & & & & & & 5 & 7 \\
\hline & $\mathrm{C}$ & & & & & & & & & 3 & & 4 & 2 \\
\hline & B & & & & & 1 & 2 & 4 & 6 & 5 & & & \\
\hline & A & 10 & 10 & 10 & 10 & 9 & 8 & 6 & 4 & 2 & & & \\
\hline \multirow{7}{*}{$\mathrm{T}_{4} 0.1-\mathrm{I}$} & G & & & & & & & 6 & 9 & 10 & \multirow{7}{*}{$\mathrm{TU}+\mathrm{T}_{4}-\mathrm{II}$} & & 2 \\
\hline & $\mathbf{F}$ & & & & & 3 & 1 & 4 & 1 & & & & 6 \\
\hline & E & & & & & 3 & 6 & & & & & 6 & 2 \\
\hline & D & & & & & 2 & 1 & & & & & 4 & \\
\hline & C & & & & 1 & 2 & 1 & & & & & & \\
\hline & B & & & 2 & 5 & & 1 & & & & & & \\
\hline & A & 10 & 10 & 8 & 4 & & & & & & & & \\
\hline \multirow{7}{*}{$\mathrm{T}_{4} 0.05-\mathrm{I}$} & G & & & & & & & 4 & 3 & 7 & \multirow{7}{*}{ Cont.-II } & 4 & 2 \\
\hline & $\mathrm{F}$ & & & & & & 2 & 2 & 7 & 3 & & 1 & 5 \\
\hline & $\mathrm{E}$ & & & & & & 2 & 2 & & & & 3 & 3 \\
\hline & D & & & & & & 2 & 1 & & & & 2 & \\
\hline & $\mathrm{C}$ & & . & & & 2 & 1 & 1 & & & & & \\
\hline & B & & & & & 5 & 3 & & & & & & \\
\hline & A & 10 & 10 & 10 & 10 & 3 & & & & & & & \\
\hline
\end{tabular}

mental period (by day 34 after hatching). In Experiment II, the fish in $\mathrm{TU}+\mathrm{T}_{4}$-II and ControlII (TU removed) were more developed than the TU-treated group (TU-II). The relationship between developmental stage of black stripes and larval size is shown in Fig. 4 (from 26 to 34 days, Experiment I). In the $T_{4}$-treated groups $\left(T_{4}-0.05\right.$ $I$ and $T_{4}$ 0.1-I), black stripes started to develop from larvae of 7-8 $\mathrm{mm} \mathrm{SL}$ and reached the final stage at $10-11 \mathrm{~mm} \mathrm{SL}$. On the other hand, TU treatment induced a developmental stasis of black stripes, i.e. no fish advanced beyond stage C (Fig. 4).

\section{Discussion}

The effects of thyroxine treatment on fish larvae are complex and various, and differ according to species and developmental stage. In general, treatment of developing fish with thyroid hor- mones induces earlier development and accelerates yolk absorption, growth and morphological differentiation or metamorphosis. ${ }^{14-18}$ ) Thyroxine enhances the growth and survival of tilapia larvae, ${ }^{17-10)}$ carp $^{20)}$ and milkfish. ${ }^{21)}$ The metamorphosis of leptocephalus of conger eel ${ }^{22)}$ and flounder larvae ${ }^{13)}$ are also influenced by thyroid hormones. In this study, although there was no significant effect on growth, there was a clear effect on the development of pigment pattern and extension of the ventral fin in the red sea bream. The effect of thyroxine treatment on pigment is known in several fish. A typical example is the silvering effect on salmonid fish, in larval development ${ }^{23)}$ and parr-smolt transformation. ${ }^{24-27)}$. This effect has also been reported for other fishes such as carp larvae ${ }^{20)}$ and milhfish post-yolk sac larvae. ${ }^{21}$ However, an effect on pigment pattern, i.e., black stripes formed by melanophores, has not yet been reported. 


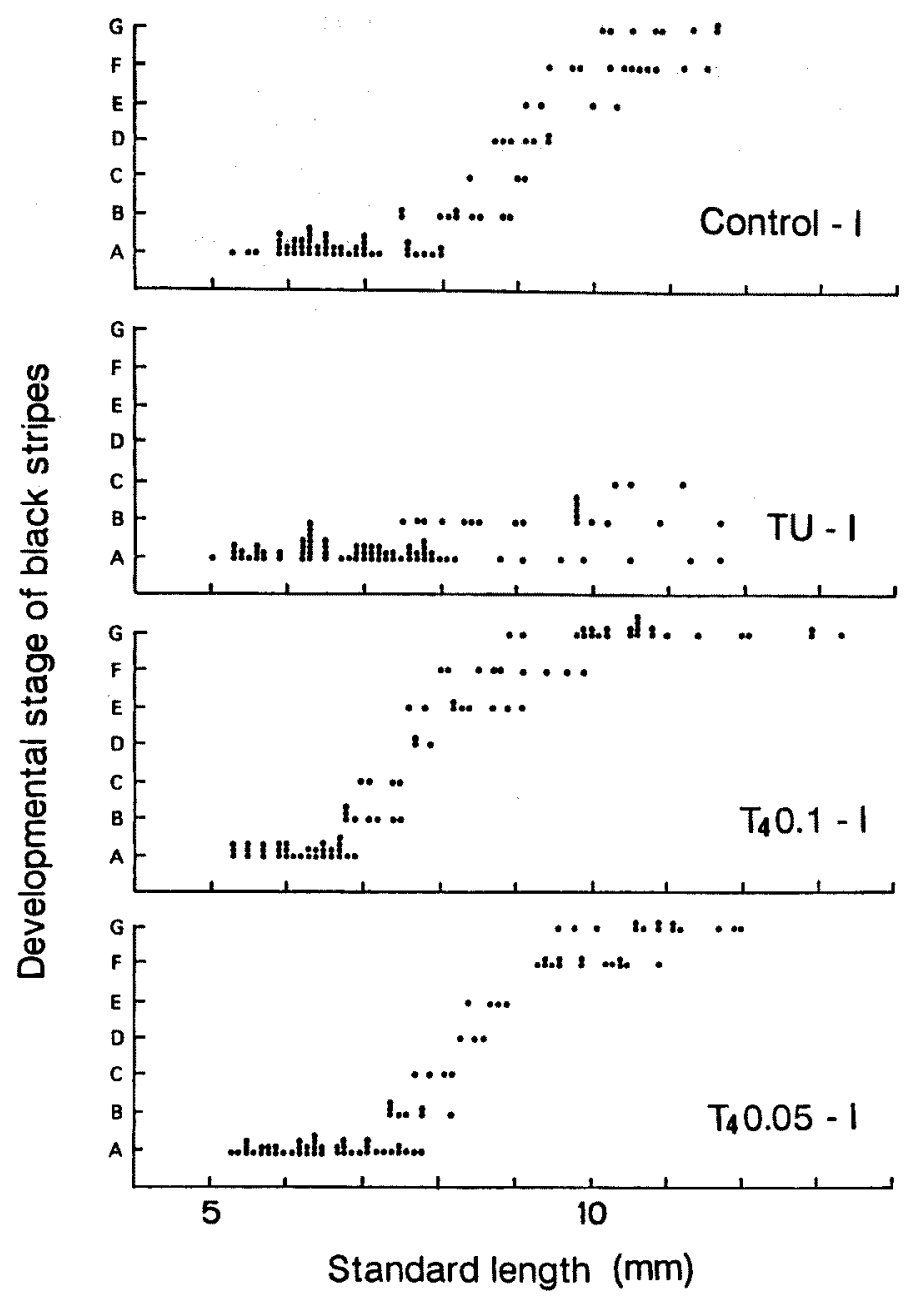

Fig. 4. Development of black stripes in relation to each standard length during Experiment $I$.

On the other hand, it is well known that the formation of black stripes is usually an indication of the change in life style such as the transition of habitat from surface to the the bottom layer, appearance of cannibalism and teritoriallity in red sea bream. ${ }^{4,5}$ In a field investigation, Tanaka ${ }^{28)}$ found that larvae of red sea bream reached $10 \mathrm{~mm}$ in total length about 30 days after hatching, when they began to metamorphose into pelagic juvniles, which migrated to the nursery ground in the bay and became demersal juveniles. Fukusho ${ }^{20)}$ also reported for Japanese parrot fish that the formation of the cross-bands is closely related to the behavior of the larval fish towards floating seaweed and a change in feeding habit. Based on the observations made during the present experiment, the change in habitat from the surface to a benthic habit coincided with development of black stripes. $T_{4}$-treated fish migrated to the bottom layer of the aquarium earlier, while most TU-treated fish remained on the surface and formed batch even at the end of the experiment. Thus, in the present study, thyroxine was shown to induce morphological and behavioural changes in red sea bream.

The relationship between thyroid hormones and behavior of fish have been studied by many investigators. Woodhead ${ }^{30)}$ reviewed the endocrine physiology of fish migration and referred to the effect of thyroid drugs on the swimming activity and schooling behavior of several fish species e.g., salmons, ${ }^{31,32)}$ goldfish, ${ }^{38)}$ trout, ${ }^{33)}$ guppy $^{34)}$ and cod. ${ }^{35)}$ Thyroid hormones are involved in the downstream migration of salmonid fish which undergo smoltification. ${ }^{30}$ ) Recently, Tsukamoto 
et al. ${ }^{\text {s7) }}$ noted a significant positive correlation between plasma $T_{4}$ and the upstream migratory behavior in Ayu. In flounder larvae, $T_{4}$ treatment induces metamorphosis and transformation form a pelagic to benthic habit. ${ }^{13)}$ However, it is still unknown whether thyroid hormone has a relationship with the drive for migration because the behavioral mechanism is not well understood. In red sea bream, although more investigation about the behavior is required, it is plausible that the transition of habitat occurred simulaneous with the development of blach stripes and ventral fin because these morphological characteristics influenced by $T_{4}$ and $T U$ were closely related to the change in habitat.

Thus, in the present study, it is clear that thyroid hormone plays an important role during the phase of transition from post-larvae to juvenile in red sea beram.

The present study also suggests that the hormonal control shown here possibly exists in larvae of many marine fish species, since it is well hnown that morphological and/or behavioral changes occur in the phase of transition from post-larva to juvenile in several fish species that do not metamorphose as drastically as the flounder. ${ }^{88)}$

\section{Acknowledgments}

We express our gratitude to Mr. T. Fushimi and staff of Hiroshima Prefectural Fisheries Experimental Station for providing facilities and larval feed for this experiment and their expert guidance in the rearing of red sea bream larvae.

\section{References}

1) O. Fukuhara: Aquiculture, 17, 71-76 (1969).

2) O. Fukuhara: Bull. Nansei Reg. Fish. Res. Lab., 9, 1-11 (1976).

3) O. Fukuhara: Bull. Nansei Reg. Fish. Res. Lab., 9, 13-18 (1976).

4) O. Fukuhara: Bull. Nansei Reg. Fish. Res. Lab., 11, 1-8 (1978).

5) O. Fukuhara: Nippon Suisan Gakkaishi, 51, 731-743 (1985).

6) M. Tanaka: Japan. J. Ichthyol., 18, 164-174 (1971).

7) C. Kitajima: Special Rep. Nagasaki Pref. Inst. Fish., 5, 1-92 (1978).

8) M. Matsuoka: Japan. J. Ichthyol., 29, 285-294 (1982).

9) K. Yamashita: Japan. J. Ichthyol., 29, 193-202 (1982).

10) K. Yamashita: Japan. J. Ichthyl., 29, 279-284
(1982).

11) H. Kohno, Y. Taki, Y. Ogasawara, Y. Shirojo, M. Taketomi, and M. Inoue: Japan. J. Ichthyol., 30, 47-60 (1983).

12) M. Matsuoka and T. Iwai: Nippon Suisan Gakkaishi, 50, 29-35 (1984).

13) Y. Inui and S. Miwa: Gen. Comp. Endocrinol., 60, 450-454 (1985).

14) A. Gorbman: in "Fish Physiology" (ed. by W. S. Hoar and D. J. Randall), Vol. 2, Academic Press, New York, 1969, pp. 241-274.

15) E. M. Donaldson, U. H. M. Fagerlund, D. A. Higgs, and J. R. McBride: in "Fish Physiology" (ed. by W. S. Hoar, D. J. Randall, and J. R. Brett), Vol. 8, Academic press, New York, 1979, pp. 455-597.

16) J. F. Leatherland: Environ. Biol. Fish., 7, 83110 (1982).

17) T. J. Lam: Aquacuiture, 21, 287-291 (1980).

18) T. J. Lam: in "Current Trends in Comparative Endocrinology" (ed. by B. Lofts and W.N. Holmes), Hong Kong Univ. Press, Hong Kong, 1985, pp. 481-485.

19) J. F. Nacario: Aquaculture, 34, 78-83 (1983).

20) T. J. Lam and R. Sharma: Aquaculture, 44, 201-212 (1985).

21) T. J. Lam, J. V. Juario, and J. Banno: Aquaculture, 46, 179-184 (1985).

22) C. Kitajima, T. Sato, and M. Kawanishi: Nippon Suisan Gakkaishi, 33, 919-922 (1967).

23) S. Dales and W.S. Hoar: Can. J. Zool., 32, 244-251 (1954).

24) W.S. Hoar: J. Fish. Res. Bd. Can., 33, 12331252 (1976).

25) H. A. Bern: in "Comparative Endocrinology" (ed. by P. J. Gaillard and H. H. Boer), Elsevier/ North-Holloand Biomedical Press, Amsterdam, 1978, pp. 97-100.

26) W. W. Dickhoff, L. C. Folmar, and A. Gorbman: Gen. Comp. Endocrinol, 36, 229-232 (1978).

27) S. Miwa and Y. Inui: Bull. Natl. Res. Inst. Aquaculture, 4, 41-52 (1983).

28) M. Tanaka: Trans. Amer. Fish. Soc., 114, 471477 (1985).

29) K. Fukusho: Japan. J. Ichthyol, 22, 23-30 (1975).

30) A. D. Woodhead: Oceanogr. Biol. Ann. Rev., 13, 278-382 (1975).

31) W.S. Hoar, D. Mackinon, and A. Redlich: Can. J. Zool., 30, 273-286 (1952).

32) W. S. Hoar, M. H. A. Keenleyside, and R. G. Goodall: Can. J. Zool., 33, $428-439$ (1955).

33) A. D. Woodhead: J. Zool., 149, 404-413 (1966).

34) M. Sage: Gen. Comp. Endocrinol, 10, 304309 (1968).

35) P. M. J. Woodhead: J. Fish. Res. Bd. Can., 27, 2337-2338 (1970).

36) L. C. Folmar and W. W. Dickhof: Aquaculture, 
21, 1-37 (1980).

37) K. Tsukamoto, K. Aida, and T. Otake: Nippon Suisan Gakkaishi, 54, 1687-1693 (1988).
38) J. H. Youson: in "Fish Physiology" (ed. by W. S. Hoar and D. J. Randall), Vol. 11, Academic Press, New York, 1988, pp. 135-196.

Nippon Suisan Gakkaishi : Formerly Bull. Japan. Soc. Sci. Fish. 